\title{
PROMOTING FORMATIVE ASSESSMENT IN MATHEMATICS TEACHER EDUCATION: AN EXPERIENCE OF DISTANCE TEACHING
}

\author{
Annalisa Cusi ${ }^{1}$, Francesca Morselli ${ }^{2}$ and Agnese Ilaria Telloni ${ }^{3}$ \\ ${ }^{1}$ Mathematics Department, Sapienza University of Rome, Piazzale Aldo Moro 5, Rome (Italy) \\ ${ }^{2}$ Mathematics Department, University of Genoa, Via Dodecaneso 35, Genoa (Italy) \\ ${ }^{3}$ Dep. of Industrial Engineering and Mathematical Sciences, Polytechnic University of Ancona \\ Via Brecce Bianche 12, Ancona (Italy)
}

\begin{abstract}
We discuss a distance teaching-learning approach, developed within two courses for prospective mathematics teachers, exploiting digital technologies to activate formative assessment practices. In particular, we analyse excerpts, from synchronous and asynchronous activities within the courses, to highlight the formative assessment processes that were activated, the feedback provided by prospective teachers to each other and their meta-reflections that testify learning in the domain of teacher education.
\end{abstract}

\section{KEYWORDS}

Distance Teaching-Learning, Teacher Education, Formative Assessment, Feedback

\section{INTRODUCTION}

Distance teaching-learning at university level has become an important focus for research in Mathematics Education. Many researchers (see, for instance, Albano \& Ferrari, 2008; Silverman \& Hoyos, 2018) stressed that e-learning, which combines face-to-face lectures and online activities by using synchronous or asynchronous tools of communication, could support students at different levels (cognitive, metacognitive and affective). Moreover, research highlighted the effectiveness, at university level, of a method aimed at activating, through digital environments, formative assessment (in the following, FA) processes, which foster collaborative work between students and effective interactions between the teacher and the students (Cusi \& Telloni, 2019; Albano et al., 2019).

In this paper we discuss an approach developed in the context of distance teaching (due to the COVID-19 emergency) within courses for prospective mathematics secondary teachers (in the following, PT). This approach, an adaptation of the one presented in Cusi \& Morselli (2018), exploits digital technologies to activate FA practices. The aim of the paper is to analyze the processes of FA developed thanks to this approach. Specifically, the paper aims at highlighting the kind of feedback that students provide to each other in relation to a task focused on the design of teaching-learning activities aimed at characterizing the key-role played by the teacher.

\section{THEORETICAL FRAMEWORK}

The theoretical framework is constituted by two main components that guided both the design of the approach adopted within our courses and the analysis of the data collected during the courses. 


\subsection{Formative Assessment in Mathematics and Key-Role of Feedback}

FA represents a fundamental element of the frame within which we develop our approach. Indeed, we think that FA could represent an effective tool to foster comparison of ideas and reflections and to the develop an effective assessment of learning in the complex domain of teacher education.

We conceive FA as a method of teaching where "[...] evidence about student achievement is elicited, interpreted, and used by teachers, learners, or their peers, to make decisions about the next steps in instruction that are likely to be better, or better founded, than the decisions they would have taken in the absence of the evidence that was elicited" (Black \& Wiliam, 2009, p.7). This method is characterized by the activation, by the three main agents within the FA processes (the teacher, the learners and their peers) of specific key-strategies that Wiliam and Thompson (2007) have identified: (A) Clarifying and sharing learning intentions and criteria for success; (B) Engineering effective classroom discussions and other learning tasks that elicit evidence of student understanding; (C) Providing feedback that moves learners forward; (D) Activating students as instructional resources for one another; (E) Activating students as the owners of their own learning.

Within the European Project FaSMEd, Wiliam and Thompson's framework has been extended, considering a further dimension, that is the functionalities of technology that could support FA (Cusi, Morselli \& Sabena, 2017): (a) sending and displaying; (b) processing and analyzing; (c) providing an interactive environment.

In FA, providing feedback represents a key-strategy to support students in reflecting about their learning processes to find out ways of overcoming their difficulties. We refer in particular to the four main levels of feedback identified by Hattie and Timperley (2007): (1) feedback about the task, which includes feedback about how well a task is being accomplished or performed; (2) feedback about the processing of the task, which concerns the processes underlying tasks or relating and extending tasks; (3) feedback about self-regulation, which addresses the way students monitor, direct, and regulate actions toward the learning goal; (4) feedback about the self as a person, which expresses evaluations and affect about the student.

\subsection{The Dialectic Theory-Practice in Teacher Education}

Our research may be inserted into the stream that focuses on mathematics teacher education, with a special focus on the need for teachers' reflection about their own practice (Jaworski, 2004) and the role of awareness in teaching (Mason, 2008). Mason claims that teacher educators should lead teachers to become aware "not simply of the fact of different ways of intervening, but of the fact of subtle sensitivities that guide or determine choices between types and timings of interventions" (p. 49), thus promoting teachers' shifts of attention toward constructs, theories, and practices that can inform and guide their future choices. As a consequence, it is important to focus on the complex interplay between theory and practice within teacher education programmes.

We refer here to the work by Cusi and Malara (2016), who propose a method for in-service teacher education that, in a former work (Cusi \& Morselli, 2018), we adapted to the case of PT. Adopting a narrative approach, already used in the field of teacher education (Lloyd, 2006; Zazkis, Sinclair and Liljedahl 2009), we asked PT to imagine and narrate what could happen in the class when the activities are implemented. As advocated by Zazkis, Sinclair and Liljedahl (2009), the activity of lesson play, that is writing a virtual dialogue between teacher and students, may foster PT' focus on the process of teaching, and finally promote their awareness. In the present contribution we present a further evolution of our method for PT education in the context of distance teaching, namely the activation of FA processes, by means of digital technologies, to support the PT' design of fictional classroom discussions and subsequent reflections on this design.

\section{RESEARCH CONTEXT AND QUESTIONS}

The study documented in this paper was carried out during the academic year 2020-21, within two courses of Mathematics Education for the master-degree in Mathematics developed at the University of Genova and at Sapienza University of Rome. Totally, 35 students attended the courses. More specifically, there were 7 students attending a laboratory course in Mathematics Education (16 hours) within the master-degree in Mathematics at the University of Genova (3 of them are enrolled in a degree in Science) and 28 students attending a course in Mathematics education (48 hours) within the master-degree in Mathematics at Sapienza 
University of Rome ( 3 of them enrolled in the master-degree course in Physics and 1 enrolled in the master-degree course in Aerospace Engineering).

The students (in the following PT) were attending their fourth year of degree course ( 5 years totally). They did not yet experience practicum, since this is usually done during the fifth year. Then, when they participated to the course, they did not have any experience in teaching.

Within the course the teacher educators (two of the authors) presented theoretical tools useful to frame the classroom activities and to analyze the roles played by the teacher during classroom discussions (one of the theoretical tools was the $\mathrm{M}_{\mathrm{AE}} \mathrm{AB}$ construct, see Cusi \& Malara 2016). Initially the teacher educators (TE) guided the PT to use the tools to analyze excerpts from real classroom discussions. Afterwards, PT were involved in these FA activities:

a. they were given tasks, and were asked to perform their a-priori analysis and to analyze some solutions of these tasks produced by students during teaching experiments;

b. they were asked to create fictional classroom discussions focused on the same tasks, explicitly referring to theoretical tools;

c. the fictional discussions were shared among the PT and each of them was asked to provide a written peer-review of at least one fictional discussion (in asynchronous mode by means of the Moodle platform);

d. the TE collected both the fictional discussions created by PT and the peer reviews to organize synchronous collective discussions, by means of the Zoom platform, aimed at sharing and analyzing the work of PT;

e. PT were asked to work in small groups and develop, during the last part of each course, the design of a complete activity, that is to create their own task, develop an a-priori analysis of the task itself, make hypothesis of possible students' answers and create the related fictional discussion starting from the students' answers;

f. the final lessons of the courses were devoted to synchronous presentations, by means of the Zoom platform, of the activities designed by groups of PT, during which a group of reviewers was asked to comment the whole design process, referring to specific guidelines provided by TE, who themselves gave feedback to the designed activities during the collective synchronous discussions.

Most of the activities were performed in small groups. Only activities b and $\mathrm{c}$ were performed individually. In this paper, we are focusing on the FA that is developed through the adaptation of our method for PT education to the context of distance teaching. More specifically, we aim at studying the feedback that are provided to PT during some of the activities of the courses.

\section{ANALYSIS}

In this paragraph we analyze, drawing from our framework, data collected from the phases $\mathrm{c}$ (asynchronous peer review on the creation of fictional classroom discussions), $d$ (synchronous collective discussions focused on the fictional discussions created by PT and guided by TE) and $\mathrm{f}$ (synchronous collective discussions focused on the presentation of the activities designed by group of PT, during which other PT acted as reviewers).

\subsection{Analysis of Excerpts from Phase C}

The starting point of the activity was the analysis of data from a teaching experiment carried out by one of the authors in grade 9. The task ("Prove that the sum of a number and its square is always an even number") referred to the first approach to algebraic proof. PT were given four solutions produced by groups of students and were asked to write down a fictional classroom discussion, starting from the data at disposal. The discussions were to be presented in a word document and accompanied by the analysis of the roles played by the teacher (referring to the $\mathrm{M}_{\mathrm{AE}} \mathrm{AB}$ construct). Students organized their product in a table: one column contained the fictional discussion, the second column contained the justification and explanation of the fictional interventions within the discussion, in terms of the theoretical tools at disposal.

PT uploaded their fictional discussions (in non-anonymous form) in a "Workshop" activity in Moodle. Afterwards, each of them was assigned randomly as a reviewer to another discussion. The task for PT was explained by the TE in a post on Moodle: "I just assigned to each of you a discussion created by one of your 
classmates, you have to "evaluate" it by next week. The "evaluation" that you are asked to do is not a "correction", rather an analysis by means of theoretical tools that we presented during the course: do you think that in the fictitious discussion the teacher is playing the roles of the $\mathrm{M}_{\mathrm{AE}} \mathrm{AB}$ construct? If possible, please indicate those interventions that you consider very efficient, and finally write a brief concluding remark".

In this way, a process of peer review (FA strategy D) was realized. Reviewers provided feedback (FA strategy C) at different levels. When commenting, they showed to the TE and their mates their degree of understanding of the theoretical tools, thus becoming responsible of their own learning (FA strategy E). Here we present some comments from the peer review and analyze them in terms of level of feedback (Hattie \& Timperley, 2007) provided to the author of the fictional discussion.

The first comment is from Alessia to Flavia and represents a feedback about the task. Alessia acknowledges that Flavia accomplished the task in a correct way, making the teacher play the expected roles: "I think the most common role played by the teacher is "investigating subject": the teacher always tries to elicit students' attitude of research and listens to the different proposals without judging them, even too much in my opinion".

The second comment, again from Alessia to Flavia, contains a feedback about the processing of the task: Alessia observes that the teacher imagined by Flavia should have intervened more, in order to promote the understanding of the meaning of proof. Alessia points out other roles that the teacher should have played in order to promote students' understanding. Besides referring to the roles of the teacher, Alessia comments in reference to the learning objective (proof): "The teacher, although saying that Group 1 just described one case, doesn't underline that "doing one example" is not sufficient as a proof. [...] The discussion seems a mere "show" of the groups' strategies, only in the shift to group 4 there is some assessment of the efficiency of the solution. What is missing is, for instance, the role of "guide in promoting a balance between semantic and syntactic dimensions": the teacher presents both verbal and algebraic approach, but does not compare them, then the students are not led to see similarities and differences between the approaches".

The third comment, from Livia to Simone, represents a feedback about the self as a person: Livia recognizes that Simone "acted" as a good teacher: "I think that Simone worked well; if it had been a real discussion, he would have involved the students in a correct way".

In some cases, reviewers wrote also some reflections that were inspired by the fictional discussion. Such reflections were intended to be shared and discussed by the whole class in a subsequent moment. We underline that the presence of these reflections is a promising fact, in terms of efficacy of the activity (discussion creation and peer reviewing) for PT education.

\subsection{Analysis of an Excerpt from Phase D}

Within this activity, the PT were asked to organize a fictional classroom discussion to be conducted during a lesson developed in the context of early algebra in grade 7, starting from a set of real answers to a task collected during a teaching experiment. The PT were asked to design a discussion aimed at a reflection on mistakes and on the different strategies carried out by students.

The following excerpt refers to a moment in the synchronous discussion, during which the TE displays three written texts from PT' fictional discussions connected to different approaches to the introduction of the discussion. In the third approach, proposed by Federica, the teacher writes at the blackboard the symbolic expressions that summarize the main students' strategies and guides the class to discuss the strategies. This approach is the one which is less in tune with the $\mathrm{M}_{\mathrm{AE}} \mathrm{AB}$ construct, so the TE, with the aim of making PT focus on strengths and weaknesses of the proposed approaches, asks to the whole group of PT to comment on them.

1. Federica: I wrote the third one and in fact I thought it was initially correct to clarify what the right answer was and to identify the wrong answers. Then each group would go to the blackboard to explain the reasoning because, at that point, it is clear what the right answer is, so there would have been a discussion from each group to understand how they reached the answer. ... The important thing is that I wanted the correct solution to be clear first, then to think about how to get there.

2. TE: Why did you choose to reformulate the solving approaches of the groups of students?

3. Federica: Because I wanted to write them mathematically to explain, verbally, how students reasoned. 
4. TE: From the choices you made, maybe you think that, if the students are those who speak at first in a discussion aimed at comparing their ideas, the risk is that the discussion will not follow the direction planned by the teacher. So, you prefer to anticipate and reformulate students' answers.

5. Federica: Yes, since I never experimented, in my experiences as student, a different kind of discussion. In my experience, it was the teacher that used to say "it is right" or "it is wrong", then each student could speak, but all the students already had the idea of what was right and what was wrong. If they do not know what is right or wrong, they do not question their answers and so they do not listen to their mates. Instead, if they know that they made a mistake and that there are different right answers, they try to understand how to reach the correct answer.

Giulio asks to comment what Federica said.

6. Giulio: I would like to say that, within an activity of this kind, I think that immediately having an idea of what the correct and incorrect answers are is demotivating because this approach establishes a hierarchy immediately. I find this approach, in general, wrong in the case in which the aim is to share strategies because it prevents the students who gave a wrong answer to reflect on the good parts of their answer.

7. Luca: I agree with Giulio. I would not say what is right and what is wrong at the beginning, since also those who gave a wrong answer could have started their reasoning in a correct way.

8. TE: I also think that, in this kind of discussions, it is better to leave some doubts, so that the class gets used to the fact that discussing their answers means learning by listening to others' point of view. This approach minimizes, in my opinion, the risk of situations in which everyone wants to defend his idea and does not listen to others. It is a matter of creating a classroom culture, in which students do not feel the need that the teacher, at the beginning, legitimizes or not their thinking processes.

Within this excerpt, the TE is activating important FA strategies. First of all, she has designed the collective synchronous discussion to make PT reflect on the approaches proposed by their colleagues, activating FA strategy B. In this excerpt, in particular, the focus is on the teaching approach proposed by Federica, in which the teacher declares what is the correct answer before activating a classroom discussion. As a result of this design, also FA strategies C and D are activated, since the other PT intervene in the discussion, proposing feedback to Federica. Both Giulio and Luca propose a feedback about the processing of the task, stressing on the limitations of Federica's approach and suggesting the positive effects of an approach in which students start to develop a classroom discussion without a-priori knowing if their answer is correct. In this discussion also the TE provides feedback to Francesca. The first feedback is about self-regulation, since the TE (line 4) interprets Federica's approach in relation to the possible reasons underlying her choice: the fear of not being able to follow a clear direction in the discussion if students are free to intervene from the very beginning of the discussion. This feedback enables Federica to explicit the deep reasons that led her to choose this approach. As a result, Federica proposes a meta-reflection focused on her past experiences, stressing that the limited experiences she had as a student influenced her choices and also her vision of classroom interaction.

The TE gives also a feedback about the processing of the task (line 8) addressed not only to Federica, but to the whole group of PT, in which she confirms Giulio and Luca's feedback, providing them with a meta-feedback (that is a feedback on the feedback) and stressing on the importance of creating a classroom culture in which students are real protagonists of discussions.

\subsection{Analysis of an Excerpt from Phase F}

We present an excerpt from the collective synchronous discussion on the activity designed by two PT, Alice and Miriam. Since Alice and Miriam's design was widely not in line with the theoretical perspectives discussed during the course, the two reviewers, Federica (the same protagonist of the excerpt analyzed in paragraph 4.2) and Clara, have identified different weaknesses of the activity in their revision work. In the following excerpt, in particular, Federica and Clara focus on the weaknesses highlighted in Alice and Miriam's design of the fictional discussion.

1. Clara: It seemed to us that the teacher uses too often expressions like "good" or formulates direct judgments to students' answers. We think that, in this way, students can become demotivated. We think it is better that students themselves assess their classmates' answers. Moreover, we think that the teacher guides too much the discussion and does not listen enough to students' proposals. 
2. Federica: You have planned to leave students time to reflect on the task before the discussion. In what way does the teacher refer to the work developed by students before the discussion? It seems that she does not consider what they did before.

3. Clara: Maybe it would be better to make students speak more, make them participate from the beginning, even in proposing the examples.

4. Miriam: We think that, in order to develop a lesson in a certain way, there is the need that the teacher is not only a participant, but that she also tries to put order within the discussion.

5. Alice: And we must consider that it is not the typical task proposed at school. This is the main reason why we decided that the teacher should guide more the discussion.

Giulia asks to intervene in the discussion.

6. Giulia: I would like to ask why expressions like "good" are considered negative within this fictional discussion. I think they could encourage students, so I cannot understand why they are negative.

7. Federica: In my opinion, it is not negative. What we wanted to say is that, as we always said during the course, if the teacher makes judgments from the very beginning, the students says "Ok, my answer is correct" or "My answer is wrong".

8. Clara: And those that gave a wrong answer could feel demoralized.

9. Giulia: But I think that, as Miriam said, in a real class, the classroom dynamics are those described by Miriam and Alice.

10. TE: The classroom dynamics are those chosen by the teacher! What Federica and Clara wanted to say is that "good!" should not be said too early in order to avoid that students do not intervene anymore. Sometimes it is better to leave a doubt and to stimulate different interventions from the students, than making a judgement that blocks the discussion.

This excerpt, like the previous one, is rich in terms of FA strategies activated and highlights the effectiveness of the choice of providing PT with specific guidelines to carry out the review process. In this way, PT were activated as resources for their classmates (FA strategy D), giving them important feedback (FA strategy C). Clara and Federica's interventions at the beginning of the excerpt (lines 1, 2, 3), in fact, represent feedback about the processing of the task since they criticize the approach chosen by Miriam and Alice, highlighting the problems connected to a too guided approach, in which the teacher, since the very beginning, makes judgements about students' answers. In particular, Federica (line 2) shows the contradictions behind the choice of giving time to students to work on the task and then not considering the work they have developed.

When reacting to this feedback, Miriam and Alice (lines 4 and 5) propose meta-reflections that explicit the deepest beliefs that guided their design, stressing that they think that this kind of activity (a problem solving activity involving students' exploration, formulation of conjectures and proof) is not usual in "normal school" and that the only way, for the teacher, of carrying out a discussion on this activity is to pose herself as a guide, not in the sense of the $\mathrm{M}_{\mathrm{AE}} \mathrm{AB}$ construct, but in the sense of someone who directs the discussion in a strict way. This point of view is shared also by another student, Giulia, who intervenes (lines 6 and 9) to defend Miriam and Alice's choice, stressing that, in her opinion, real classes are not those on which the design of fictional discussion is focused. When reacting to Giulia' interventions, Federica and Clara (lines 7 and 8) propose meta-reflections in which they explicit the new awareness reached thanks to the previous activities of the course. As in the previous transcript, the meta-reflections are about a previous experience lived by the PT who propose them: in the case of Miriam, Alice and Giulia, they refer to a vision of teaching that collides with the theoretical tools introduced during the course, a vision strictly linked to past experiences (as students); in the case of Federica, the meta-reflection refers to a new vision of teaching that she has developed thanks to her experience within the course. We can highlight a change in Federica's vision about the effective way of designing a classroom discussion and we interpret this change in terms of Federica's professional learning.

Finally, we stress that also in this excerpt the TE intervenes, only at the end (line 10), to reformulate Clara and Federica's comments in order to legitimize the feedback they give (therefore providing a meta-feedback), so that they can really become resources for Miriam, Alice and Giulia and for the whole group of PT in general. 


\section{CONCLUSIONS}

In this paper, we discussed a distance teaching-learning approach, developed within two courses for PT. The wide range of FA processes highlighted through our analysis of excerpts testifies the effectiveness of this approach in exploiting the functionalities of digital technologies to activate FA practices. In fact, the sending and displaying functionality of technology supported the TE in collecting, organizing and sharing students' written materials, making these materials become fundamental objects of reflections for PT. Moreover, our adaptation of the method for PT education to the context of distance teaching massively exploited the providing an interactive environment functionality, since the designed asynchronous and synchronous activities enabled TE and PT to effectively interact, contributing, thanks to the feedback provided to each other, to their own development of new awareness about the processes in which they were involved.

Thanks to our analysis, we adapted the use of Hattie and Timperley's levels of feedback to the context of teacher education, where the tasks are at a professional level: (1) feedback about the task refers to an effective use of the theoretical tools for the design of fictional discussions; (2) feedback about the processing of the task concerns the choices made within the design process and their effects in terms of learning objectives; (3) feedback about self-regulation refers to the factors that influence the design process; (4) feedback about the self as a person projects the PT in their future profession.

We also discussed the key-role of the teacher educator in both designing effective discussions to reflect on PT' fictional discussions and in legitimating, through meta-feedback, the different types of provided feedback. Moreover, we highlighted PT' meta-reflections during the discussions carried out within the courses, interpreting their reactions to the feedback as both evidences of their deepest beliefs about teaching and hints of the growing awareness they developed through their participation into the courses' activities.

As a further development, we plan to deepen this last part of our analysis to identify categories of meta-reflections.

\section{REFERENCES}

Albano, G. and Ferrari, P.L., 2008. Integrating technology and research in mathematics education: the case of e-learning. In F.J. Garcia Peñalvo (Ed.), Advances in E-Learning: Experiences and Methodologies. IGI Global, Hershey, PA, pp. 132-148.

Albano, G., Pierri, A. and Sabena, C., 2019. Enhancing formative assessment practices in undergraduate courses by means of online workshop. Proceedings of ICTMT 14. Essen, Germany, pp. 155-162.

Black, P. and Wiliam, G., 2009. Developing the theory of formative assessment. Educational Assessment, Evaluation and Accountability, Vol. 21, No. 1, pp. 5-31.

Cusi, A. and Telloni, A. I., 2019. The role of formative assessment in fostering individualized teaching at university level. Eleventh Congress of the European Society for Research in Mathematics Education. Utrecht, Netherlands, pp. 4129-4126.

Cusi, A. and Malara, N.A. 2016. The Intertwining of Theory and Practice: Influences on Ways of Teaching and Teachers' Education. In L. English, \& D. Kirshner (Eds.), Handbook of International Research in Mathematics Education 3rd Edition. Taylor \& Francis, London, pp. 504-522.

Cusi, A. and Morselli, F., 2018. Linking theory and practice: prospective teachers creating fictional classroom discussions. Proceedings of PME 42. Umeå, Sweden, pp. 323-330 (Vol. 2).

Cusi, A., Morselli, F. and Sabena, C., 2017. Promoting formative assessment in a connected classroom environment: design and implementation of digital resources. ZDM Mathematics Education, 49 (5), 755-767.

Hattie, J. and Timperley, H., 2007. The power of feedback. Review of Educational Research, Vol. 77, No. 1, pp. 81-112.

Jaworski, B., 2004. Grappling with complexity: Co-learning in inquiry communities in mathematics teaching development. Proceedings of PME 28. Bergen, Norway, pp. 17-36 (Vol. 1).

Lloyd, G.M., 2006. Preservice teachers' stories of mathematics classrooms: explorations of practice through fictional accounts. Educational Studies in Mathematics, Vol. 63, pp. 57-87.

Mason, J., 2008. Being mathematical with and in front of learners. In B. Jaworski \& T. Wood (Eds.), International handbook of mathematics teachers education. Sense Publishers, Rotterdam, Vol. 4, pp. 31-55.

Silverman, J \& Hoyos, V. (Eds.), 2018. Distance Learning, E-Learning and Blended Learning of Mathematics. ICME-13 Monographs. Springer, Cham, Switzerland.

Wiliam, D. and Thompson, M., 2007. Integrating assessment with instruction: What will it take to make it work?. In C. A. Dwyer (Ed.), The future of assessment: Shaping teaching and learning. Erlbaum, Mahwah, NJ, pp. 53-82.

Zazkis, R., Liljedahl, P., \& Sinclair, N., 2009. Lesson Play - A vehicle for multiple shifts of attention in teaching. In B. Davis \&S. Lerman (Eds.), Mathematical Action \& Structures of Noticing: Studies inspired by John Mason. Sense Publishers, Rotterdam, pp.165-177. 